\title{
Algorithm-based decision support for symptom self-management among adults with Cancer: results of usability testing
}

Mary E. Cooley ${ }^{1 *}$, Janet L. Abrahm², Donna L. Berry ${ }^{3}$, Michael S. Rabin, Ilana M. Braun², Joanna Paladino², Manan M. Nayak ${ }^{1}$ and David F. Lobach ${ }^{5,6}$

\begin{abstract}
Background: It is essential that cancer patients understand anticipated symptoms, how to self-manage these symptoms, and when to call their clinicians. However, patients are often ill-prepared to manage symptoms at home. Clinical decision support (CDS) is a potentially innovative way to provide information to patients where and when they need it. The purpose of this project was to design and evaluate a simulated model of an algorithmbased CDS program for self-management of cancer symptoms.

Methods: This study consisted of three phases; development of computable algorithms for self-management of cancer symptoms using a modified ADAPTE process, evaluation of a simulated model of the CDS program, and identification of design objectives and lessons learned from the evaluation of patient-centered CDS. In phase 1, algorithms for pain, constipation and nausea/vomiting were developed by an expert panel. In phase 2, we conducted usability testing of a simulated symptom assessment and management intervention for self-care (SAMI-Self-Care) CDS program involving focus groups, interviews and surveys with cancer patients, their caregivers and clinicians. The Acceptability E-scale measured acceptability of the program. In phase 3, we developed design objectives and identified barriers to uptake of patient-centered CDS based on the data gathered from stakeholders.
\end{abstract}

Results: In phase 1, algorithms were reviewed and approved through a consensus meeting and majority vote. In phase 2, 24 patients \& caregivers and 13 clinicians participated in the formative evaluation. Iterative changes were made in a simulated SAMI-Self-Care CDS program. Acceptability scores were high among patients, caregivers and clinicians. In phase 3, we formulated CDS design objectives, which included: 1) ensure patient safety, 2) communicate clinical concepts effectively, 3) promote communication with clinicians, 4) support patient activation, and 5) facilitate navigation and use. We identified patient barriers and clinician concerns to using CDS for symptom self-management, which were consistent with the chronic care model, a theoretical framework used to enhance patient-clinician communication and patient selfmanagement.

Conclusion: Patient safety and tool navigation were critical features of CDS for patient self-management. Insights gleaned from this study may be used to inform the development of CDS resources for symptom self-management in patients with other chronic conditions.

Keywords: Rule-based clinical decision support, Symptom management, Patient engagement, Patient self-management, Cancer

\footnotetext{
* Correspondence: mary_cooley@dfci.harvard.edu

${ }^{1}$ The Phyllis F. Cantor Center, Dana-Farber Cancer Institute, 450 Brookline

Avenue, Boston, MA 02115, USA

Full list of author information is available at the end of the article
}

(c) The Author(s). 2018 Open Access This article is distributed under the terms of the Creative Commons Attribution 4.0 International License (http://creativecommons.org/licenses/by/4.0/), which permits unrestricted use, distribution, and reproduction in any medium, provided you give appropriate credit to the original author(s) and the source, provide a link to the Creative Commons license, and indicate if changes were made. The Creative Commons Public Domain Dedication waiver (http://creativecommons.org/publicdomain/zero/1.0/) applies to the data made available in this article, unless otherwise stated. 


\section{Background}

Patient-centered healthcare is one of six aims to improve the United States healthcare system [1]. One facet of patient-centered care is engaging patients and encouraging self-management, especially in the context of chronic illness. Self-management programs that provide coaching and education, and are supported by timely information, facilitate patient engagement $[2,3]$.

Given the frequency of symptoms from cancer and its treatment, it is essential that patients (and their caregivers) understand how to self-manage symptoms and when to call their clinicians for advice. McCorkle and colleagues [3-5] noted that most patients with cancer try to self-manage their care and that developing system-level interventions to support self-management is essential for quality cancer care. Evidence-based strategies to assist patients with selfmanagement include: education, telephone consultations, Internet tools for tracking disease-specific parameters, and coaching [3, 6-13]. Such interventions targeted information management, medications, psychological consequences of illness, lifestyle, social support, communication, accessing services, and setting goals [14-16]. Self-management interventions decreased the severity of pain [17], fatigue [18], and depression [19]. Web-based interventions, featuring self-monitoring, education and coaching of patients combined with summaries of patient-reported data delivered to clinicians, led to improvement in symptom distress and quality of life $[12,16,20]$. Evidence suggests that reporting symptoms to clinicians alone may not be sufficient. A project in which patients receiving chemotherapy reported on symptoms using an automated phone system failed to impact care. Even though symptoms of moderate to severe intensity were reported, clinicians did not provide patients with management guidance [10].

Considering the variability of clinician response to symptom reports, an optimal approach to enhance selfmanagement includes providing patient-specific, realtime, actionable information. Supplying Clinical Decision Support $(C D S)$ directly to patients may enhance their ability to self-manage symptoms. $C D S$ "provides individuals with person-specific information, intelligently filtered or presented at appropriate times, to enhance health" [21]. Four studies have described rule-based CDS tools for cancer patients. [12, 20, 22, 23] In two studies, CDS was used to identify the presence of a symptom using an algorithm with a single decision node that generated general recommendations for symptom management [12, 22]. In studies by Berry and colleagues [24] and Weaver, [23] the focus was self-care support and identifying symptoms to report to clinicians. Berry and colleagues [12] found that Web-based coaching of patients to report symptom experiences verbally resulted in more frequent reports during clinic visits, but the investigators did not document how often a participant called the clinic to ask for help. Ruland et al. [20] developed a Web-based resource that assisted patients with assessing symptoms, finding information, communicating with clinic personnel and provided self-management advice. This tool was evaluated and showed a slight decrease in symptom distress for patients [20] but the CDS component was not evaluated independently for its effect. A follow-up study determined that communication with nurses was the most valued component [25].

The present study extends the literature by reporting on the design and formative evaluation of an algorithmbased simulated model of a patient-centered CDS program that facilitates cancer symptom self-management, provides advice on when patients should contact their clinicians, and includes coaching information about what to tell them. The goals of the project were to develop computable algorithms for pain, constipation and nausea/vomiting in phase 1 , conduct iterative usability testing of the simulated CDS program called the Symptom Assessment and Management Intervention for SelfCare (SAMI-Self-Care) with patients, their caregivers and clinicians in phase 2, and develop design objectives and identify barriers to uptake of patient-centered CDS based on the data gathered from stakeholders, which included members of an expert panel, patients, caregivers, and their clinicians in phase 3 .

\section{Methods}

We employed a convergent, parallel, mixed methods design, [26] in which we collected qualitative and quantitative data in parallel, analyzed it separately, and then merged all data during interpretation, to evaluate the acceptability of a simulated algorithm-based CDS program for cancer symptom self-management. This study was conducted at Dana-Farber Cancer Institute (DFCI) and approved by the Institutional Review Board (IRB), Protocol number-12-300.

Phase 1: Algorithm-based CDS intervention development In order to develop the patient-centered CDS algorithms, we used a modified ADAPTE process [27-29] consisting of five steps; 1) identify expert panels to develop and evaluate the computable algorithms, 2) develop groups to work on each symptom and synthesize the literature, 3) convene groups to translate evidence-based information into computable algorithms for each symptom, 4) conduct peer review on the content of the algorithms before convening a multidisciplinary consensus meeting, and 5) hold a multidisciplinary panel meeting to review, modify and approve the algorithms.

The study team identified areas of expertise that were critical for developing and evaluating an algorithm-based CDS tool for symptom self-management. Individuals with the desired expertise were identified through existing professional relationships or through recommendations of 
colleagues. The identified individuals were invited to join the panel by the principal investigator (MEC) and included: stakeholders with expertise in clinical care (oncologists, palliative care experts, psychiatrists, and oncology nurses), information systems (experts in CDS, patient data collection, health communication, and graphic design), care delivery process (experts in workflow, quality improvement, and health equity), as well as patients and caregivers.

Our expert panel drew from evidence-based resources and worked with CDS experts to develop computable algorithms that would enable self-management of pain, constipation, and nausea/vomiting. Overall, the expert panel met four times for $4 \mathrm{~h}$ each time to review the algorithms developed by the research team. The symptoms chosen were the most common reasons for urgent care among cancer patients and identified as important targets for symptom management by patients and their caregivers in a previous study that explored patient preferences for CDS to enhance clinical care [30]. Our process of developing algorithms was based on our previous work that adapted evidence-based guidelines for clinicians [31]. Similar to our previous work, multidisciplinary groups were formed for each symptom and serial meetings were held to develop the initial algorithms. Once the algorithms were completed, a group meeting with the members of the research team and the expert panel was held to review, modify and approve the algorithms. For each symptom, characteristics were identified to direct self-management. Characteristics of pain included descriptors of neuropathic or somatic pain, and a measure of intensity (moderate, severe). Features of nausea/vomiting included chemotherapy-induced, radiation-induced, chemoradiation-induced, acid reflux, vertigo, recent narcotic increase, anticipation of chemotherapy, and constipation. Characteristics of constipation included frequency and consistency of stool.

\section{Phase 2: Usability testing}

In order to refine the algorithm content and the simulated SAMI-Self-Care tool display and function iteratively, we used a collaborative-participatory approach. This approach engaged stakeholders in a shared co-designing process and helped ensure that the product will meet reallife needs and be adopted [32, 33]. The team formulated a scenario for a symptom management dilemma that would allow patient users to traverse the self-care management algorithms so that self-management recommendations could be generated. Cognitive testing was performed for each algorithm by reviewing the content displayed on an iPad with patients and their caregivers to ensure that these questions were clear, understandable, and relevant, and that the response options were appropriate prior to initiating the iterative usability testing. Cognitive testing of items is recommended as a standard approach to the development process as it allows one to ascertain whether participants understand items on a questionnaire and allows for iterative changes before finalizing questions [34].

This patient-vetted algorithm content was given to the Dana-Farber Harvard Comprehensive Cancer Center Health Communication Core. The Core developed a mockup of the SAMI-Self-Care using interactive PDF files to simulate the function of the CDS tool based on expert panel input and clinical informatics literature [35, 36]. The PDF files imitated the functionality of a Website and allowed participants to experience the "look and feel" of a potential operational CDS system on an iPad. This approach provided a practical and economical approach to usability testing, especially during formative stages of development when iterative refinement is necessary. The Health Communication Core also designed reports containing self-management recommendations to elicit feedback from participants regarding report content and appearance. A series of focus groups or interviews were conducted to elicit feedback about the CDS program. Using a multi-methods approach (i.e. focus groups and interviews) is appropriate when the intent is to gather information that is focused on specific goals and questions, which in this case was participant response about the usability of an algorithm-based CDS program [37]. We used a combination of methods to provide flexibility to participants to be able to participate in the usability sessions. We used the same facilitator to conduct the focus groups and interviews and used an interview guide to elicit information about the usability and acceptability of the SAMI-Self-Care CDS program.

Based on feedback from the expert panel, patients, caregivers, and clinicians, we iteratively created three successive versions of the SAMI-Self-Care program. Figures 1, 2, 3, 4 show the iterative development of the self-management report that was generated for participants based on responses to the questions and algorithm-based CDS. Feedback from the usability testing was used to inform the changes that were made to the CDS program and the self-management report (see results).

\section{Participant recruitment}

Patients were identified through medical records at DFCI under a waiver of consent authorization, and names were submitted to their clinicians for approval to contact patients, as required by the IRB. Eligible patients were age $\geq$ 18, English speaking, and had received cancer treatment within the past 6-months. All approved patients were sent an initial letter describing the study and inviting them to participate. Patients received two follow-up calls if they didn't respond to the letter. Patients identified caregivers to invite to participate in the study. Eligible caregivers 


Symptom Assessment and Management Intervention for Patients
SAMI-Self Care
Pain that is achy or sharp AND
\[ \begin{array}{l}\text { Pain that is burning or shooting or numb } \\ \text { Severe pain keeping you up at night AND }\end{array} \]
Keep taking short acting medication as prescribed and call your doctor or nurse during
fice hours, reporting how often you need to take it.
Continue taking the longer-acting medication(s) while you adjust to your short-acting pain
hedication(s).
help manage your achy or sharp pain:
Start 200 mg of ibuprofen three times a day and
call your doctor or nurse during normal business hours to let them know you
have made change to your medication.

Fig. 1 Initial SAMI-Self Care report

were age $\geq 18$ years and provided care to a patient who received cancer treatment within the past 6-months. Deliberate efforts were made to sample across a range of diagnoses, educational backgrounds, ages, genders, and races. All participants signed consent forms at the time of participation. Each participant received $\$ 50$ for completing the study.

Clinicians in ambulatory oncology included physicians, nurse practitioners, physician assistants, and registered nurses. Clinicians were identified through clinic rosters. An invitation to participate in the study was emailed to eligible clinicians. Two follow-up emails were sent if no response was received. Clinicians were recruited for either focus groups or interviews depending on their schedules. Clinicians received an invitation letter describing the study but signed consent was waived by the IRB. Each clinician received $\$ 100$ for completing the study.

\section{Focus group and interview processes}

Focus groups and interviews were held separately for clinicians and patients/caregivers. Focus groups included up to five participants; interviews included one or two participants and were held in a convenient conference room at DFCI. Meetings for clinicians lasted about $30 \mathrm{~min}$ whereas those for patients and caregivers lasted 45$60 \mathrm{~min}$. One symptom was addressed per session. Using a script, the facilitator queried patients, caregivers and clinicians about the algorithm content of the SAMI-SC programs for constipation, pain, and nausea/vomiting, and asked about the "look and feel" of the materials for pain and nausea/vomiting. The topics for patients and caregivers focused on the: 1) visual appeal, 2) format and navigation, 3) understandability of written content and terminology, and 4) wording of self-management suggestions. The topics for the clinicians focused on 1) a review of the patient self-management algorithms, 2) review of the simulated SAMI-Self-Care CDS program, and 3) feedback about ways to improve the algorithms and/or simulated model. Patients/caregivers and clinicians reported demographic data using a standardized survey.

The number of sessions per symptom was determined by evidence of content saturation and absence of new common responses [38]. With patients/caregivers, we conducted six sessions for pain, seven sessions for nausea/ 
SYMPTOM ASSESSMENT AND MANAGEMENT INTERVENTION FOR SELF-CARE [SAMI-SC]

\section{Your symptom report: _ Pain}

Based on your answers to the questions, it sounds like:

- You have severe pain

- You have pain that is achy or sharp

- You have pain that is burning, shooting, or numb that is keeping you up at night

\section{Specific ways to help your pain:}

1. It sounds like: For your severe pain, you have taken your short-acting medication, and your pain returned before it was time for the next dose. You also took your long-acting pain medication and are still having severe pain.

Do this: Keep taking your short-acting pain medication as prescribed, and call your doctor or nurse during normal business hours to see if you can take it more often. Keep taking your long-acting pain medication while your short-acting pain medication gets adjusted.

2. It sounds like: You are having achy or sharp pain and are not taking any ibuprofen.

Do this: Take $200 \mathrm{mg}$ of ibuprofen as needed, and call your doctor or nurse during normal business hours to let them know about this change to your medication. If you are not already taking a medication to protect your stomach, also ask your doctor or nurse about taking a medication to protect your stomach when taking medication to manage sharp or achy pain. These medications could include:

- Omeprazole

- Pantoprozole

Fig. 2 First revision for SAMI-Self Care report

vomiting, and three sessions for constipation. With clinicians, we conducted two sessions for pain, three sessions for nausea/vomiting, and one session for constipation. All discussions were audio-recorded and transcribed.

\section{Survey instruments}

The Acceptability E-scale measured the acceptability of the CDS program [39]. This scale has been used in adult patients with various types of cancers from medical oncology, radiation oncology and stem cell transplant to measure acceptability of Web-based systems, including computerized symptom and quality of life assessments, patient educational materials and patient-centered decision support. Psychometric testing was conducted in 627 adults with cancer $[40,41]$. Cronbach alpha reliability coefficient was 0.75 and factor analysis revealed that the scale was unidimensional [39]. Five-point Likert-type items (1-5; larger number equals higher acceptability and a score of 3 indicates a neutral response) were presented to elicit feedback from both patient/caregiver and clinician participants regarding: 1) understandability of language, 2) helpfulness of suggestions provided for symptom self-management, 3) usefulness of reports, and 4) overall satisfaction with the program. The a priori target for acceptability of SAMI-Self-Care was a mean score of $\geq 4$ on each item since this score indicated a positive acceptability response. In addition to the Acceptability E-scale, participants were asked what other types of information would have been helpful for symptom self-management. The scale took less than 2 min to complete and was written at a 5 th grade reading level.

\section{Analysis}

Patient/caregiver and clinician demographic data were summarized as descriptive statistics. Acceptability E-scale results were summarized as item means and standard deviations.

Audio-recorded session content was transcribed and reviewed by three study team members (MEC, DFL, $\mathrm{MMN}$ ), coded inductively, and grouped into common 
SYMPTOM ASSESSMENT AND MANAGEMENT INTERVENTION FOR SELF-CARE [SAMI-SC]

\section{Your recommendations for: _ Pain}

Based on your answers to the questions, it sounds like:

- You have severe pain

- You have pain that is achy or sharp

- You have pain that is burning, shooting, or numb that is keeping you up at night

\section{Specific ways to help your pain:}

1. It sounds like: For your severe pain, you have taken your short-acting medication, and your pain returned before it was time for the next dose. You also took your long-acting pain medication and are still having severe pain.

Do this:

- Keep taking your short-acting pain medication as prescribed

- Important but not urgent: Call your doctor or nurse during their regular working hours at 617-632-9999 and ask if you can take your short-acting pain medication more often.

- Keep taking your long-acting pain medication while your short-acting pain medication gets adjusted.

2. It sounds like: You are having achy or sharp pain and are not taking any ibuprofen.

Do this:

- Take $200 \mathrm{mg}$ of ibuprofen as needed.

- Important but not urgent: Call your doctor or nurse during their regular working hours at 617-632-9999 to let them know about this change to your medication.

- If you are not already taking a medication to protect your stomach, also ask your doctor or nurse about taking a medication to protect your stomach when taking medication to manage sharp or achy pain. Common medications to protect the stomach include:

- Omeprazole (Prilosec)

- Pantoprozole (Protonix)

Fig. 3 Second revision for SAMI-Self Care report

responses to identify revisions that needed to be made in the CDS tool. Common responses were then combined and reconciled though discussion. A list of suggested revisions to improve SAMI-Self-Care algorithms and the simulated model was created and ranked based on audio files and notes. Critical revisions were implemented immediately, while other less critical revisions were monitored for repetition. This process was repeated, after each iteration of CDS tool development, until no new responses or suggestions for changes emerged from the usability testing. Phase 2 analyses focused on the revisions that needed to be make to the CDS tool.

\section{Phase 3: Design objectives and barriers to uptake of patient-centered CDS}

Once all the data were collected and the usability testing completed, three investigators (MEC, DFL, MMN) reviewed all of the qualitative data in order to identify design objectives and barriers to uptake of the patientcentered CDS program. Eight sessions were needed to organize the data collected from the expert panel, patients, caregivers and clinicians and discuss the themes that were identified through inductive content analysis [42]. These data were then shared and discussed with other members of the research team to generate a final list of design objectives, patient barriers, and clinician concerns to use of the CDS program.

\section{Analyses}

Audio-recorded session content was transcribed and reviewed by three study team members (MEC, DFL, MMN), coded, and grouped into themes. Themes were then combined and reconciled though discussion. Inductive analyses of the coded qualitative data for phase 3 focused on interpreting patient barriers to using the CDS program, defining clinician concerns about use of CDS by patients/caregivers, and identifying strategies to overcome the areas of concern. It was noted during the analysis that the themes that emerged from the qualitative data were consistent with the Chronic Care Model 
SYMPTOM ASSESSMENT AND MANAGEMENT INTERVENTION FOR SELF-CARE [SAMI-SC]

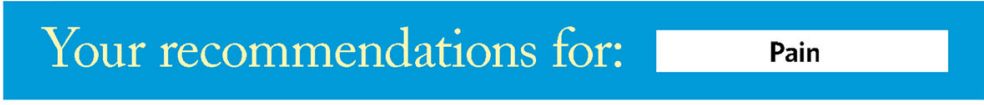

Based on your answers, it sounds like:

- You have severe pain, have already taken your short-acting medication, and your pain returned before the next dose

- You have burning, shooting, numb, or "pins and needles" pain that is keeping you up at night.

- You have pain that is sharp or achy and are not taking any ibuprofen.

\section{Do now:}

- Take $200 \mathrm{mg}$ of ibuprofen as needed for your sharp or achy pain.

- Keep taking your short-acting and long-acting pain medications as prescribed.

\section{Do next:}

Call your doctor or nurse during regular working hours at 617-632-9999 and:

- Ask if you can take your short-acting pain medication more often

- Ask if you can increase your nighttime dosage of gabapentin (Neurontin)

- Tell them you are taking $200 \mathrm{mg}$ of ibuprofen as needed AND

- If you are not already taking a medication to protect your stomach, ask about taking one when taking medication (like ibuprofen) to manage sharp or achy pain. Common medications for stomach protection include:

- Omeprazole (Prilosec)

- Pantoprozole (Protonix)

Fig. 4 Third revision for SAMI-Self Care report

$[3,43]$. Thus, five design objectives detailed below (in Results) were developed to address these concerns. As a result, content analysis was then used to regroup the themes to fit within the Chronic Care Model.

\section{Results}

\section{Phase 1: Rule-based CDS intervention development}

Nine potential participants were approached for membership in the expert panel, and all accepted the invitation. Altogether, 16 members of the research team and expert panel contributed to algorithm development. Work sessions were conducted in person and by Web conferencing so that the flow charts could be displayed more easily for discussion. Branching logic was used to develop the algorithms and these were displayed as flow charts that were shared among all team members. Research staff provided support to access current guidelines that were available for the targeted symptoms and to assist with literature reviews. Each work group had someone assigned who was expert in pharmacological, non-pharmacological and self-management approaches so that a comprehensive approach to enable selfmanagement would be embedded into the algorithms.

Once the development of the algorithms and usability testing was completed, a multidisciplinary consensus meeting was held with the expert panel, research team and co-investigators to review, modify and approve the final versions. In order to iteratively improve the program, the expert panel focused on several issues. The primary issue was patient safety. Safety was addressed by identifying potential serious causes of each symptom and directing patients to seek contact with their clinicians. Accordingly, all three algorithms began with the identification of "red flag symptoms" that caused patients a forced exit of the CDS tool and a directive to call a clinician immediately for guidance. A second issue was how to make the tool accessible to patients across a range of health literacies. Our solution was to provide information that patients could elect to review or skip based on their needs. A third issue was how to provide medication-related advice that was aligned with 
therapies recommended by a patient's clinician. To address this issue, we asked the patient whether the medication we were recommending for the problem (e.g. senna for constipation) was approved by his/her clinician. If it was approved, we inquired whether the patient had taken that medication. If not, the patient was advised to take it. If the patient had not been prescribed the recommended therapy, he or she was advised to contact his/her clinician and inquire if this therapy could be appropriate. The resulting algorithms had a large number of decision nodes ranging from 51 to 257 (moderate and severe pain combined). A decision node is a point in the algorithm where the logic branches into two or more directions. A higher number of decision nodes reflect greater algorithmic complexity [44]. Table 1 provides information about the number of decision nodes and red flag questions that were present within each symptom algorithm. A simple majority vote was taken at the end of the discussion surrounding each symptom algorithm to determine whether agreement was reached regarding modifications and approval. Table 1 provides an overview of the number of red flags that were required for each symptoms and the complexity of the algorithms.

\section{Phase 2: Usability testing \\ Participant sample}

One-hundred-and-three patients were screened to identify the 24 patients and caregivers for study inclusion (Table 2). Twenty-six patients were deemed ineligible by their clinicians due to the incapacitating nature of their condition and 14 did not meet other eligibility criteria or could not be contacted. Seventeen potential subjects declined participation; 22 indicated interest but were unable to attend scheduled sessions or did not respond to scheduling requests. Participating patients and caregivers were predominately Caucasian, almost evenly split between men and women and most had some college level education.

Forty-four clinicians were contacted to identify 13 who participated in focus groups and interviews (Table 3). Of the clinicians who did not participate, 20 did not respond, 2 declined, and 9 indicated interest but were unable to attend scheduled sessions. Clinician participants were predominately female and Caucasian.

Table 1 Number of decision nodes and red flag questions in each symptom algorithm

\begin{tabular}{lll}
\hline Symptom & Decisional Nodes & Red Flag Questions \\
\hline Nausea \& Vomiting & 54 & 6 \\
Pain & 257 & $2^{\mathrm{a}}$ \\
$\quad 125$ & \\
Severe Pain & 122 & \\
Moderate Pain & 51 & 4 \\
\hline
\end{tabular}

${ }^{a}$ Red flag questions are the same for both the moderate and severe pain pathways
Table 2 Cancer Patient and Caregiver Demographics ( $N=24)$

\begin{tabular}{|c|c|c|}
\hline Characteristic & $n$ & $\%$ \\
\hline \multicolumn{3}{|l|}{ Role } \\
\hline Patient & 15 & 63 \\
\hline Caregiver & 9 & 37 \\
\hline \multicolumn{3}{|l|}{ Gender } \\
\hline Female & 13 & 54 \\
\hline \multicolumn{3}{|l|}{ Age } \\
\hline Median/Range & 55 & $21-69$ \\
\hline$<50$ & 5 & 21 \\
\hline$\geq 50$ & 19 & 79 \\
\hline \multicolumn{3}{|l|}{ Race } \\
\hline Caucasian & 20 & 83 \\
\hline Black/African American & 2 & 8 \\
\hline Other & 2 & 8 \\
\hline \multicolumn{3}{|l|}{ Ethnicity } \\
\hline Hispanic & 4 & 17 \\
\hline Non-Hispanic & 18 & 75 \\
\hline Did Not Report & 2 & 8 \\
\hline \multicolumn{3}{|l|}{ Education } \\
\hline High School or Less & 3 & 12 \\
\hline Some College or More & 21 & 88 \\
\hline \multicolumn{3}{|l|}{ Income } \\
\hline$\$ 49,999$ or Less & 4 & 17 \\
\hline$\$ 50,000$ or More & 19 & 79 \\
\hline Did Not Report & 1 & 4 \\
\hline \multicolumn{3}{|l|}{ Cancer Type ( $n=15$ ) } \\
\hline Hematologic Malignancies & 5 & 33 \\
\hline Solid Tumor Malignancies & 10 & 67 \\
\hline \multicolumn{3}{|l|}{ Types of Solid Tumor } \\
\hline Breast & 1 & 7 \\
\hline Gastrointestinal & 3 & 20 \\
\hline Genitourinary & 1 & 7 \\
\hline Gynecologic & 1 & 7 \\
\hline Head and Neck & 1 & 7 \\
\hline Neuro-oncology & 1 & 7 \\
\hline Thoracic & 2 & 13 \\
\hline \multicolumn{3}{|c|}{ Internet Use to Obtain Health Information } \\
\hline Never/Rarely & 0 & 0 \\
\hline Sometimes & 10 & 42 \\
\hline Often/Nery Often & 13 & 54 \\
\hline Missing & 1 & 4 \\
\hline
\end{tabular}

\section{Focus groups and interviews}

Patients and caregivers provided feedback about the visual appeal of the program, especially related to the color scheme, text density, and font size. Participant feedback 
Table 3 Oncology Clinician Demographics ( $N=13)$

\begin{tabular}{|c|c|c|}
\hline Characteristic & $n$ & $\%$ \\
\hline \multicolumn{3}{|l|}{ Gender } \\
\hline Female & 11 & 85 \\
\hline \multicolumn{3}{|l|}{ Race } \\
\hline Caucasian & 11 & 84 \\
\hline Black/African American & 1 & 8 \\
\hline Asian & 1 & 8 \\
\hline \multicolumn{3}{|l|}{ Ethnicity } \\
\hline Non-Hispanic & 11 & 85 \\
\hline Did Not Report & 2 & 15 \\
\hline \multicolumn{3}{|l|}{ Training } \\
\hline Physicians & 3 & 23 \\
\hline Nurse Practitioners & 4 & 31 \\
\hline Physician Assistants & 2 & 15 \\
\hline Registered Nurses & 4 & 31 \\
\hline \multicolumn{3}{|l|}{ Cancer Specialty Area } \\
\hline Hematologic Malignancies & 4 & 31 \\
\hline Solid Tumor Malignancies & 9 & 69 \\
\hline \multicolumn{3}{|l|}{ Types of Solid Tumor } \\
\hline Gastrointestinal & 2 & 15 \\
\hline Genitourinary & 1 & 8 \\
\hline Neuro-oncology & 1 & 8 \\
\hline Head and Neck & 1 & 8 \\
\hline Thoracic & 2 & 15 \\
\hline Radiation Oncology & 1 & 8 \\
\hline General Practice & 1 & 8 \\
\hline \multicolumn{3}{|c|}{ Prior Use of Patient-Focused Information Tools } \\
\hline Never/Rarely & 8 & 61 \\
\hline Sometimes/Often/Very Often & 5 & 39 \\
\hline
\end{tabular}

sought to make the display inviting and easy to read. Some of the issues raised by clinicians who viewed the program were similar to issues identified by patients and their caregivers. For example, clinicians made suggestions about use of language, decreasing the density of text and providing graphic images to enhance understanding. For the most part, patients, caregivers and clinicians had similar comments to enhance the usability of the program. However, clinicians provided additional feedback about the content of the algorithms, and to ensure patient safety. They suggested adding questions at the beginning of the algorithms that would identify potentially dangerous symptoms that needed immediate attention and prompt patients to exit the program and call their clinicians. We also found that clinicians disagreed about what were best practices for self-management in pain management. Some clinicians felt that patients with pain levels of $\geq 9$ should not self-manage and call their clinicians immediately, whereas others felt that it was acceptable to use the suggestions and then call their clinicians for refractory pain. Tables 4 and 5 provide an overview of comments provided by participants to improve the usability of the program.

\section{Acceptability surveys}

Participants completed surveys regarding the acceptability of SAMI-Self-Care for "nausea/vomiting" and "pain" after each round of system development and viewing the simulated interface. Nine patients and their caregivers completed surveys, four assessing pain and five assessing nausea and vomiting. Two rounds of assessment for usability and acceptability were conducted with patients to reach or surpass the predetermined threshold for acceptability. In general, patients found the system easy to understand and helpful for self-management.

Thirteen clinicians completed surveys, nine assessed pain and three assessed nausea and vomiting, and one assessed constipation. Two rounds of assessment for usability and acceptability were conducted with clinicians. The simulated program for nausea/vomiting and constipation reached and surpassed the threshold for acceptability. However, the helpfulness of suggestions for the pain algorithm was scored lower than our target threshold of 4.0. For the most part, clinicians also viewed the system for pain as usable and helpful. Subsequent discussions revealed that some clinicians felt that patients with a pain score $\geq 9$ should contact their clinicians and not pursue self-management. The algorithm was subsequently changed to reflect that patients with severe pain, should contact their clinicians, but time limitations prevented the modified algorithm from being reevaluated.

\section{Phase 3: Design Objectives and Barriers to Patient- centered CDS Design objectives}

From patient, caregiver, and stakeholder feedback, we identified five design objectives that were relevant for the development of algorithm-based patient-centered CDS, which included: ensure patient safety, communicate clinical concepts effectively, promote communication with clinicians, support patient activation, and facilitate navigation (see Table 6). This table includes information about the design objective, specific stakeholder barriers related to this objective, solutions that were identified to address the barrier and changes that were made in the user interface. A discussion surrounding each of these design objectives is found in the following section followed by some barriers to patientcentered CDS that emerged from our findings. 
Table 4 Results of Usability Testing for the SAMI-Self-Care CDS Program: Patient Perspectives

\begin{tabular}{|c|c|c|c|}
\hline Usability Testing Themes & CDS Tool Content* & $\begin{array}{l}\text { CDS Tool } \\
\text { Component** }\end{array}$ & Examples \\
\hline Visual appeal & $\begin{array}{l}\text { Comments about introductory pages } \\
\text { that had a lot of content }\end{array}$ & $\begin{array}{l}\text { Visual appeal } \\
\text { and design }\end{array}$ & "Some pages seem overwhelming." \\
\hline \multirow[t]{23}{*}{$\begin{array}{l}\text { Understanding } \\
\text { of terminology }\end{array}$} & Pain severity question & $\begin{array}{l}\text { Written content } \\
\text { and terminology }\end{array}$ & "What does 'bearable pain' mean?" \\
\hline & $\begin{array}{l}\text { Medication questions for all } \\
\text { symptoms }\end{array}$ & $\begin{array}{l}\text { Written content } \\
\text { and terminology }\end{array}$ & "What does 'able and willing' [to take a medication] mean?" \\
\hline & Nausea and vomiting question & $\begin{array}{l}\text { Written content } \\
\text { and terminology }\end{array}$ & "Position change- does that mean when I lift my head up?" \\
\hline & Medication questions & $\begin{array}{l}\text { Written content } \\
\text { and terminology }\end{array}$ & "Unclear about the word 'dose' in the questions." \\
\hline & Medication question & $\begin{array}{l}\text { Written content } \\
\text { and terminology }\end{array}$ & $\begin{array}{l}\text { "Did you take the dose you were due for? Does that mean } \\
\text { the dose time already passed or the next dose I am } \\
\text { due for?" }\end{array}$ \\
\hline & Pain quality question & $\begin{array}{l}\text { Written content } \\
\text { and terminology }\end{array}$ & $\begin{array}{l}\text { "Define what type of pain you are referring too", is it "pokey } \\
\text { pain, electrical current, shock pains burning pains, etc." }\end{array}$ \\
\hline & Pain quality question & $\begin{array}{l}\text { Written content } \\
\text { and terminology }\end{array}$ & $\begin{array}{l}\text { "I wouldn't have categorized numbness as pain...I'm glad } \\
\text { it's there." }\end{array}$ \\
\hline & Pain severity question & $\begin{array}{l}\text { Written content } \\
\text { and terminology }\end{array}$ & $\begin{array}{l}\text { "I like 'faces' as part of the pain scale. They make the pain } \\
\text { measure more clear." }\end{array}$ \\
\hline & Constipation definition & $\begin{array}{l}\text { Written content } \\
\text { and terminology }\end{array}$ & $\begin{array}{l}\text { "Definitions were too wordy, for example, constipation } \\
\text { definition had too much information." }\end{array}$ \\
\hline & Pain medication list & $\begin{array}{l}\text { Written content } \\
\text { and terminology }\end{array}$ & $\begin{array}{l}\text { "I have trouble understanding meaning or relevance to } \\
\text { words such as Morphine or Opioids." }\end{array}$ \\
\hline & Constipation medication list & $\begin{array}{l}\text { Written content } \\
\text { and terminology }\end{array}$ & "Is Senna tea the same as Senna medication?" \\
\hline & $\begin{array}{l}\text { Nausea and vomiting red flag safety } \\
\text { questions }\end{array}$ & $\begin{array}{l}\text { Written content } \\
\text { and terminology }\end{array}$ & "What are two glasses of water per day?" \\
\hline & All symptom medication questions & $\begin{array}{l}\text { Written content } \\
\text { and terminology }\end{array}$ & $\begin{array}{l}\text { "Need to add a time frame to the question: 'Did you take } \\
\text { your medication?"' }\end{array}$ \\
\hline & $\begin{array}{l}\text { General content related to } \\
\text { introduction of program } \\
\text { and definition of all symptoms }\end{array}$ & $\begin{array}{l}\text { Written content } \\
\text { and terminology }\end{array}$ & $\begin{array}{l}\text { Simplicity of terminology required for some patients with } \\
\text { little medical sophistication makes clinical concepts difficult } \\
\text { to communicate and can be tedious for more medically } \\
\text { sophisticated patients. }\end{array}$ \\
\hline & Nausea and vomiting questions & $\begin{array}{l}\text { Written content } \\
\text { and terminology }\end{array}$ & $\begin{array}{l}\text { "Why are you asking me about acid reflux and then position } \\
\text { change? Are they related?" }\end{array}$ \\
\hline & $\begin{array}{l}\text { Nausea and vomiting red flag safety } \\
\text { questions }\end{array}$ & $\begin{array}{l}\text { Written content } \\
\text { and terminology }\end{array}$ & "Why is bone marrow transplant question asked?" \\
\hline & Pain red flag safety questions & $\begin{array}{l}\text { Written content } \\
\text { and terminology }\end{array}$ & $\begin{array}{l}\text { Reason for why some questions are asked is not } \\
\text { understood, e.g., "Not everyone has back pain." }\end{array}$ \\
\hline & Nausea and vomiting questions & $\begin{array}{l}\text { Written content } \\
\text { and terminology }\end{array}$ & $\begin{array}{l}\text { "Some patients may be getting some agents that aren't } \\
\text { considered chemotherapy but the patient thinks they are } \\
\text { getting chemo." }\end{array}$ \\
\hline & $\begin{array}{l}\text { Constipation questions and } \\
\text { medication lists }\end{array}$ & $\begin{array}{l}\text { Written content } \\
\text { and terminology }\end{array}$ & $\begin{array}{l}\text { "I didn't know that morphine and opioids can cause } \\
\text { constipation." }\end{array}$ \\
\hline & $\begin{array}{l}\text { Pain and nausea and vomiting } \\
\text { medication questions }\end{array}$ & $\begin{array}{l}\text { Written content } \\
\text { and terminology }\end{array}$ & $\begin{array}{l}\text { "Don't you want to know exact time and date of } \\
\text { [a medication] dose?" }\end{array}$ \\
\hline & Pain questions and medication list & $\begin{array}{l}\text { Written content } \\
\text { and terminology }\end{array}$ & $\begin{array}{l}\text { Word "narcotic" brought up negative feelings it was "a } \\
\text { scary word." }\end{array}$ \\
\hline & Pain question and medication list & $\begin{array}{l}\text { Written content } \\
\text { and terminology }\end{array}$ & "I know narcotic is bad for you." \\
\hline & $\begin{array}{l}\text { General comment from bilingual } \\
\text { participants }\end{array}$ & $\begin{array}{l}\text { Written content } \\
\text { and terminology }\end{array}$ & "Is this available in Spanish?" \\
\hline
\end{tabular}


Table 4 Results of Usability Testing for the SAMI-Self-Care CDS Program: Patient Perspectives (Continued)

\begin{tabular}{|c|c|c|c|}
\hline Usability Testing Themes & CDS Tool Content* & $\begin{array}{l}\text { CDS Tool } \\
\text { Component** }\end{array}$ & Examples \\
\hline \multirow[t]{5}{*}{ Format and navigation } & $\begin{array}{l}\text { Pain and nausea and vomiting } \\
\text { medication questions }\end{array}$ & $\begin{array}{l}\text { Format and } \\
\text { navigation }\end{array}$ & $\begin{array}{l}\text { "Can we input all the medications we are taking into } \\
\text { the system?" }\end{array}$ \\
\hline & All symptom assessment questions & $\begin{array}{l}\text { Format and } \\
\text { navigation } \\
\text { Suggestions to } \\
\text { improve }\end{array}$ & $\begin{array}{l}\text { "Add checkboxes to make this [the entry of symptoms] } \\
\text { easier." }\end{array}$ \\
\hline & All symptom questions & $\begin{array}{l}\text { Written content } \\
\text { and terminology }\end{array}$ & "Create an option of 'I don't know." \\
\hline & $\begin{array}{l}\text { General comment about iPad } \\
\text { functionality }\end{array}$ & $\begin{array}{l}\text { Format and } \\
\text { navigation }\end{array}$ & $\begin{array}{l}\text { "Are there instructions for those who are not computer } \\
\text { users to know how to use this function?" (Referring to } \\
\text { functionality of hovering over a definition for more } \\
\text { information.) }\end{array}$ \\
\hline & General comment on iPad & $\begin{array}{l}\text { Format and } \\
\text { navigation }\end{array}$ & "Use 'back' instead of 'previous."' \\
\hline \multirow[t]{3}{*}{$\begin{array}{l}\text { Wording of } \\
\text { self-management suggestions }\end{array}$} & $\begin{array}{l}\text { General comment for instructions for } \\
\text { call clinicians on report }\end{array}$ & $\begin{array}{l}\text { Written content } \\
\text { and terminology }\end{array}$ & "I don't want to bother my care team." \\
\hline & $\begin{array}{l}\text { General comment for instructions to } \\
\text { call clinicians on report }\end{array}$ & $\begin{array}{l}\text { Written content } \\
\text { and terminology }\end{array}$ & "When should I contact my care team?" \\
\hline & $\begin{array}{l}\text { General comment for instructions to } \\
\text { call clinicians on report }\end{array}$ & $\begin{array}{l}\text { Written content } \\
\text { and terminology }\end{array}$ & "What should I tell my care team?" \\
\hline \multicolumn{4}{|l|}{ Other } \\
\hline \multirow[t]{3}{*}{ Patient safety } & Pain report suggestions & $\begin{array}{l}\text { Written content } \\
\text { for report }\end{array}$ & "Is it safe for me to take this medication?" \\
\hline & $\begin{array}{l}\text { Nausea and vomiting red flag safety } \\
\text { questions }\end{array}$ & $\begin{array}{l}\text { Written content } \\
\text { for safety } \\
\text { questions }\end{array}$ & $\begin{array}{l}\text { "Are we allowed to drink } 2 \text { large glasses a liquid per day? } \\
\text { Shouldn't we ask the doctor first?" }\end{array}$ \\
\hline & Constipation report suggestions & $\begin{array}{l}\text { Written content } \\
\text { for suggestions }\end{array}$ & "Is it safe for me to initiate the proposed intervention?" \\
\hline \multirow[t]{2}{*}{ Resources } & Constipation suggestions & Other concerns & "Do I have suggested medications in my home?" \\
\hline & General comment about iPad & $\begin{array}{l}\text { Format and } \\
\text { navigation }\end{array}$ & $\begin{array}{l}\text { "Some people will lack the technology to access the } \\
\text { system." }\end{array}$ \\
\hline
\end{tabular}

* CDS tool content refers to what aspect of the CDS tool that the comment sought to improve (i.e. medication vs. pain severity question)

** CDS tool component refers to what aspect of the CDS tool that the component that the comment sought to improve (i.e. written content vs. visual appeal)

\section{Ensure patient safety}

To ensure that the use of SAMI-Self-Care would not overlook a life-threatening condition, we identified a set of screening questions for each symptom that sought to direct patients with potentially dangerous conditions to stop using the algorithm and seek contact with their clinicians. To ensure that the advice provided through SAMI-Self-Care was sound, we derived algorithm logic and recommendations from evidence-based clinical guidelines. When appropriate, we also inquired if a recommended therapy had already been suggested by the patient's clinician. If the therapy had not been suggested, we encouraged the patients to check with their clinician to request approval before initiating a new medication.

\section{Communicate clinical concepts effectively}

In order to communicate clinical concepts effectively, we conducted cognitive testing of content with patients to ensure an adequate level of understanding, and we added graphics to support concepts in the text when appropriate. We also designated a section of the display for explanations or lists so that patients who needed more information could easily access it. Formative testing of questions through the cognitive interviewing process helped us to recognize that we needed to make questions as explicit and detailed as possible so patients were not left to speculate about how to respond. Finally, we used established interface development practices for screen appearance, layout, and text fonts to enhance readability [45].

\section{Promote communication with clinicians}

To encourage communication with patients' clinicians, we included explicit suggestions regarding when to contact their clinicians and a script for what to say to them. We also advised patients to notify their clinicians within a specified time frame about interventions they may have followed from SAMI-Self-Care. 
Table 5 Results of Usability Testing for the SAMI-Self-Care CDS Program: Clinician Perspectives

Usability Testing CDS Tool Context* CDS Tool Component** Examples

Themes

\begin{tabular}{|c|c|c|}
\hline \multirow[t]{2}{*}{ Visual appeal } & $\begin{array}{l}\text { General comment related to } \\
\text { the look and feel of the system }\end{array}$ & Format \\
\hline & Nausea and vomiting & Format \\
\hline \multirow[t]{6}{*}{$\begin{array}{l}\text { Understanding of } \\
\text { terminology }\end{array}$} & Pain severity question & $\begin{array}{l}\text { Written content and pref } \\
\text { for terminology }\end{array}$ \\
\hline & Nausea and vomiting question & Written content \\
\hline & Pain question & Written content \\
\hline & Nausea and vomiting & Format \\
\hline & All symptoms & Written content and form \\
\hline & Pain & Written content \\
\hline \multirow[t]{6}{*}{$\begin{array}{l}\text { Format and } \\
\text { navigation }\end{array}$} & $\begin{array}{l}\text { Comment about introduction } \\
\text { and orientation to the program }\end{array}$ & Format \\
\hline & Nausea and vomiting question & $\begin{array}{l}\text { Written content and algo } \\
\text { This related to the issue } \\
\text { chemotherapy induced } \\
\text { may be more common } t \\
\text { position-induced nausea }\end{array}$ \\
\hline & $\begin{array}{l}\text { Comment to improve the look and feel } \\
\text { of the program }\end{array}$ & Format and navigation \\
\hline & $\begin{array}{l}\text { Provide an introduction to } \\
\text { questions so patients will } \\
\text { know what to expect and why }\end{array}$ & Format and navigation \\
\hline & $\begin{array}{l}\text { General comment related to } \\
\text { sequencing of questions }\end{array}$ & Format and navigation \\
\hline & $\begin{array}{l}\text { General comment about } \\
\text { sequence of questions }\end{array}$ & Written content \\
\hline \multirow{2}{*}{$\begin{array}{l}\text { Wording of } \\
\text { self-management } \\
\text { suggestions }\end{array}$} & Symptom reports & Written content \\
\hline & Symptom reports for red flag questions. & Written content \\
\hline
\end{tabular}

$\begin{array}{ll}\text { Symptom reports } & \text { Written content } \\ \text { Symptom reports } & \text { Written content }\end{array}$

Symptom reports Written content

Other

$\begin{array}{ll}\text { Patient safety } & \text { All symptoms red flag } \\ & \text { questions developed for safety }\end{array}$

Pain red flag safety questions Algorithm content
"Use larger fonts and colors as a way to distinguish instructions from question."

"Give a visual description of what a 16-oz container might look like, e.g., a Poland spring water bottle."

Disapproval of wording, "bearable pain."

"Clearly indicate what issue is being evaluated, e.g., [for] position change, are we asking about getting up quickly or vertigo?"

"Add timeframes, e.g., did taking the pain mediation offer you relief after 30 min?"

"Add graphics such as [a picture of] fire in the esophagus, which doesn't need a definition."

"Medication lists might be overwhelming for some patients."

"Offer educational explanation such as risk factors regarding why the patients shouldn't take certain medication, e.g., for ibuprofen explain why stomach protection is needed for those 65 or older."

"Select a symptom that is bothering the patients the most, and then come back to evaluate other symptoms."

s. "Prioritize question order based on frequency of issues experienced by the patients to reduce number of questions patients have to answer and to avoid patients having to answer questions to symptoms majority might not experience."

"Try to reduce the number of clicks needed to move the system forward, e.g., they shouldn't have to select the symptom and press next to move forward."

"Tell patients upfront the different symptoms or medications the program will ask about."

"Add skip patterns for those who might have used the system before."

"Work on lessening redundancy of the questions."

"Be clear with instructions regarding communication w/ clinicians."

"Clearly indicate to the patient to call now, so they do not mistakenly think the report has been automatically sent to their clinician and that someone will follow up."

"Educate the patient on how to use the paging service."

"Don't put 'during normal business hours' because it sounds like we're telling patients to stop bothering us."

"List phone number of clinician on the report or a paging service for after hours."

Identify all red flag/emergency issues.

"Ask about new or severe pain not just one [or the other] and, [a] 'yes' [response] should mean call your doctor right away." 
Table 5 Results of Usability Testing for the SAMI-Self-Care CDS Program: Clinician Perspectives (Continued)

\begin{tabular}{|c|c|c|c|}
\hline $\begin{array}{l}\text { Usability Testing } \\
\text { Themes }\end{array}$ & CDS Tool Context* & CDS Tool Component** & Examples \\
\hline & $\begin{array}{l}\text { General comment about reports } \\
\text { that are generated for self-management }\end{array}$ & Written content & $\begin{array}{l}\text { Clinicians worried that they may not be informed } \\
\text { about patient problems. }\end{array}$ \\
\hline & All symptoms red flag questions added & Algorithm content & $\begin{array}{l}\text { Clinicians concerned they may miss or overlook } \\
\text { critical situations. }\end{array}$ \\
\hline & General comment about the report & Written content & $\begin{array}{l}\text { "Include notification to patient that they should } \\
\text { always call provider with questions." }\end{array}$ \\
\hline & General comment & Written content & $\begin{array}{l}\text { "Wouldn't want the patient to use the program } \\
\text { instead of getting care." }\end{array}$ \\
\hline Resources & General concern about use of iPad & Format & $\begin{array}{l}\text { Concern that some patients will not have access to } \\
\text { computers. }\end{array}$ \\
\hline \multirow[t]{5}{*}{ Best care practices } & Pain self-management for severe pain & $\begin{array}{l}\text { Written content about when } \\
\text { to call their clinicians }\end{array}$ & $\begin{array}{l}\text { Lack of consensus among clinicians regarding clinical } \\
\text { best practices. }\end{array}$ \\
\hline & Nausea and vomiting acid reflux & Algorithm content & $\begin{array}{l}\text { Some providers recommend medication like TUMS, } \\
\text { but Gl doctors may avoid it because it creates acid. }\end{array}$ \\
\hline & Pain and nausea and vomiting & $\begin{array}{l}\text { Written content wanted more } \\
\text { comprehensive lists for } \\
\text { medications }\end{array}$ & $\begin{array}{l}\text { Recommended some medications be added on to } \\
\text { lists [of medications already included]. }\end{array}$ \\
\hline & Pain medication question & Written content & "Change dosing criteria for long acting to 8-12 h." \\
\hline & Pain medication lists & Written content & $\begin{array}{l}\text { "Certain medications on the list not used across the } \\
\text { board causing worry, e.g., fentanyl or tapentadol." }\end{array}$ \\
\hline
\end{tabular}

\section{Support patient activation}

We sought to engage patients by providing personalized and actionable instructions. As appropriate, we asked patients about resource availability and their willingness to follow interventions prior to making recommendations. Through the educational display section, we provided content to help patients understand why certain questions were being asked and why specific recommendations were provided. Helpful features included suggestions for pharmacologic and non-pharmacologic therapies.

\section{Facilitate navigation and use}

To expedite SAMI-Self-Care use we identified methods to optimize traversal of the algorithms and minimize the burden of data entry (see Table 6). We included a progress bar for patients to know their position in the process, and we added capabilities to change responses or to pause a session. We also added display content to enable a patient to recognize the context of every interaction through tabs illustrating the symptom being addressed and text clarifying the context of each question. Finally, we ensured that all pathways could be traversed, were unique and not redundant.

\section{Barriers that need to be addressed to promote patient- centered CDS}

Barriers to promote patient-centered CDS regarding symptom self-management that emerged appeared to be consistent with the Chronic Care Model so the themes that emerged were reorganized around the components of this model which included: patient safety, cultural competency, care coordination, resource availability, and acceptance of technology.

Barriers pertaining to cultural competency were the most common and included challenges related to unfamiliar terminology, lack of reference to a clinical framework, and unusual health beliefs. Although many of the concerns identified by patients were shared by clinicians, a few items were unique to patients and their caregivers, including expressing uncertainty about some self-management suggestions and whether the actions would be acceptable to their clinicians, expressing negative health beliefs associated with the use of narcotic medications, and not having the suggested medications available at home. There also were concerns about communication with their clinicians, availability of technology in the community, and use of the technology.

\section{Discussion}

We developed a simulated algorithm-based CDS program to support symptom self-management among adults with cancer and their caregivers. Our CDS program is more complex than other previously developed programs and provides patents with specific information, tailored to their situation regarding when to call their clinician, what to tell them, and how to self-manage their symptoms. In order to accomplish this task, we have many more decisional nodes than previous patient- 


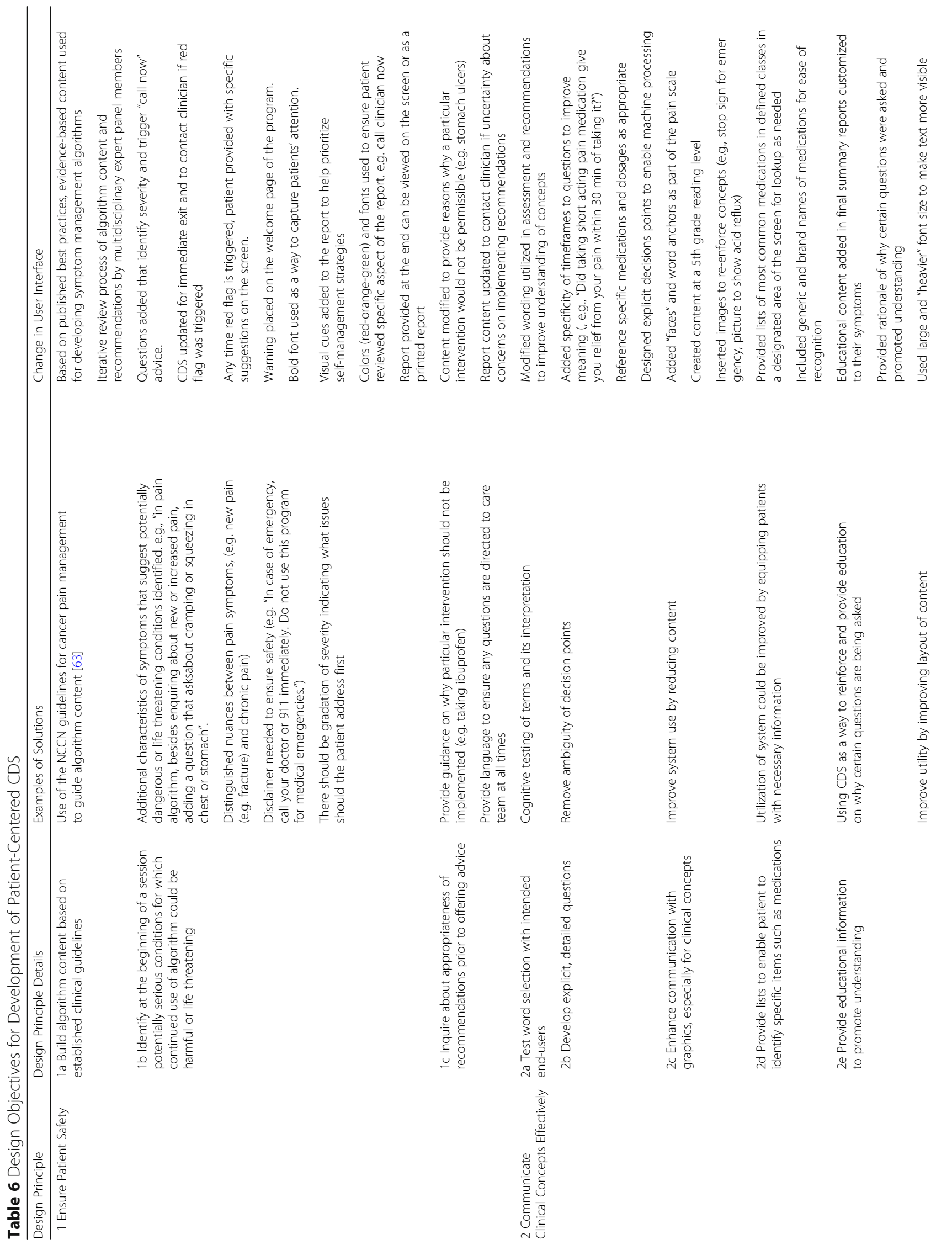




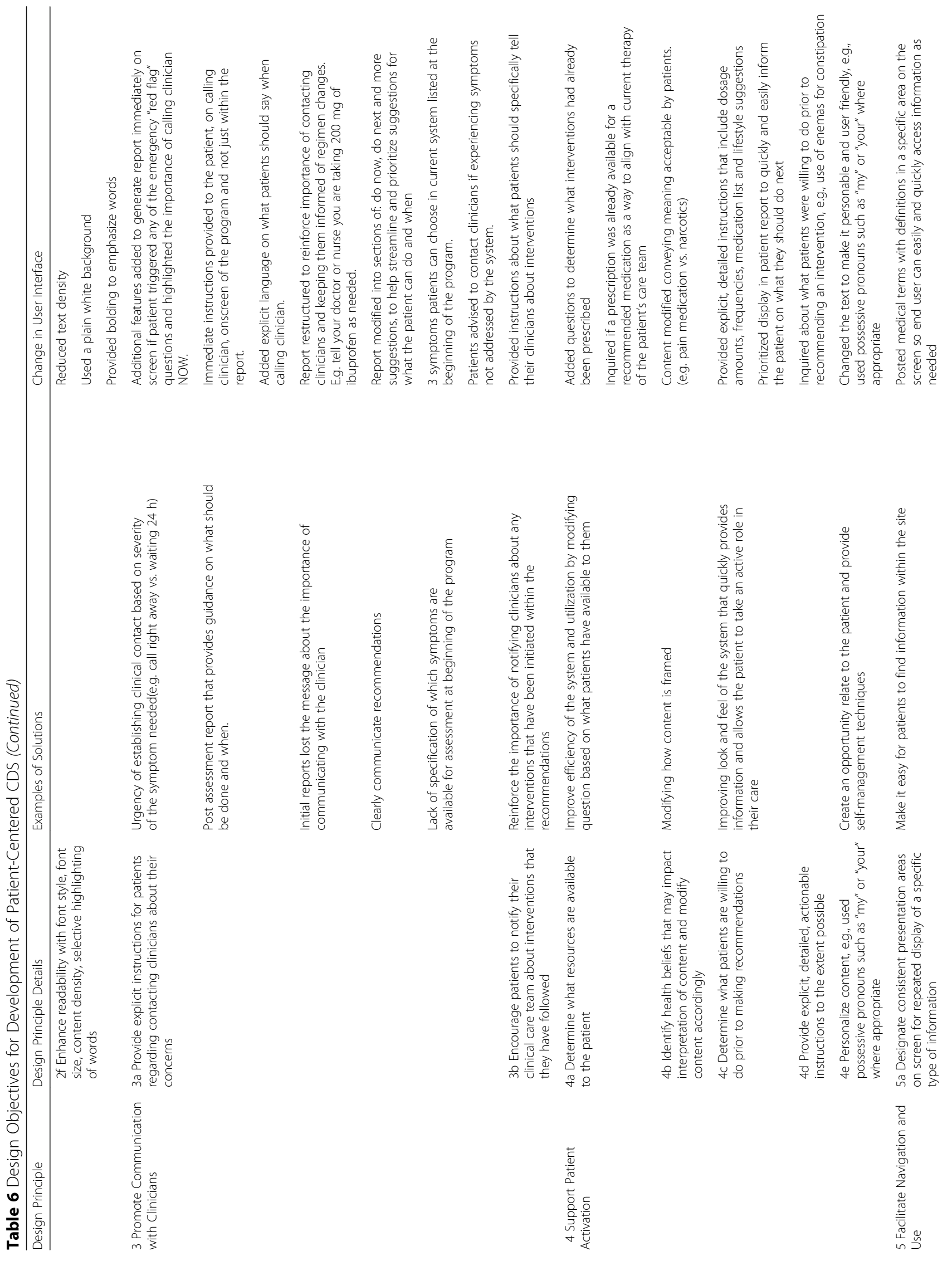




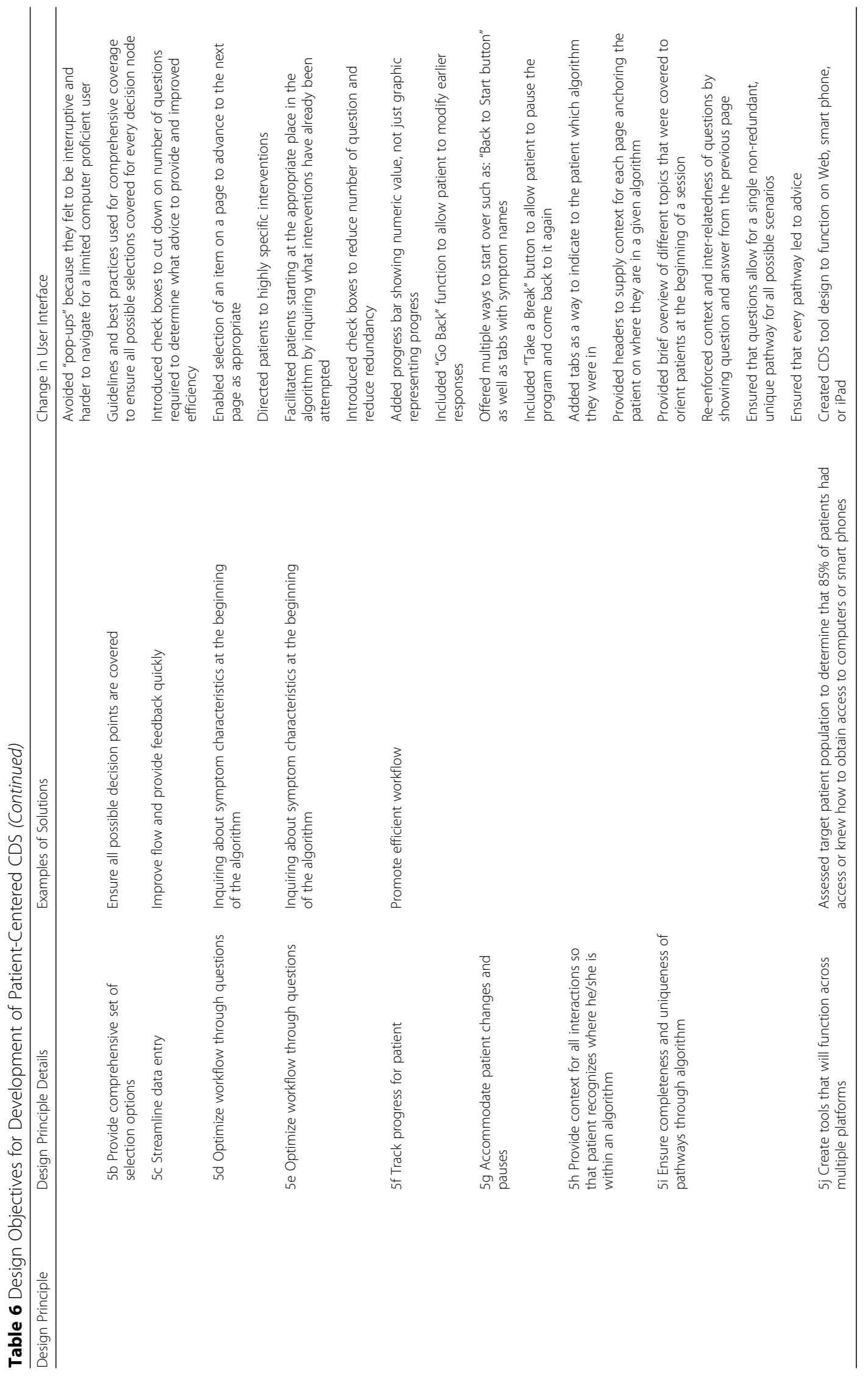


centered CDS systems [12, 22]. Acceptability testing results among patients were favorable, suggesting that patients found the SAMI-Self Care prototype a satisfactory approach to for symptom self-management. Providing CDS directly to patients may be a valuable tool. Future studies should explore the best modalities for providing access to these tools including the Web, tablet computers, or mobile phones [46]. We anticipate that the SAMI-Self-Care tool could be implemented on a Webbased platform that could be accessible across computers, tablets and smartphones. A link to this content could be inserted in the homepage of a patient's oncology treatment group or sent out directly to patients through electronic mail.

We noted that the acceptability results from clinicians for pain were less favorable than for nausea/vomiting and constipation, and were below our desired threshold of 4.0 for helpfulness of the report and suggestions. This result required obtaining a larger sample size to gather responses about usability testing as compared to other symptoms. In spite of our efforts to adhere to pain guidelines, [47] some clinicians were reluctant to support self-management because they wanted to remain aware of their patients' symptoms and to be directly involved in management. This finding is interesting as implementation of pain guidelines has been a challenge. Evidence suggests that pain management practices have not changed over the last twenty years and many patients with cancer continue to experience severe uncontrolled pain [48, 49]. Further study is needed to understand clinician attitudes toward pain management and barriers to encouraging patient self-care management. One concern that clinicians expressed is that they wanted to be aware of patients who had severe levels of pain. The addition of a system that alerts clinicians when patient symptoms pass a predetermined level of severity would address this concern. Cleeland and colleagues [13] found that automated symptom severity alerts after surgery for lung cancer reduced symptom distress. In a recent study that examined clinician preferences for CDS, the use of an alerting system for increased symptom severity was identified as a desirable component [50].

Our design objectives were specifically developed in this study to support development of effective patient-focused CDS. To date, CDS design objectives have focused on use by clinicians. Thus, even though our CDS system was designed for patients, we sought to include features known to be associated with effective CDS systems for clinicians $[35,36,51]$. The system features identified in our study that were similar to clinician CDS included: graphics to enhance understanding of content; explicit, actionable recommendations provided at the point of decision-making; presentation of advice that cultivated trust by providing an explanation of medical logic if needed [36]. In addition, similar to Bates and colleagues, [35] our Design Objectives focused on streamlining the user interaction by decreasing the number of questions needed to inform the algorithm, targeting anticipated needs with advice in real-time, providing supplemental information as needed but without interruption, and relying on a user-centered iterative design [43]. Ozkaynak and colleagues [52] noted that an important difference between patient and clinician design for CDS is integrating technology into the user's work flow. Designing CDS around clinician work flow is much easier than for patient work flow as clinicians function within a health system, whereas work flow for patients spans multiple health care settings and includes home, routines of daily living and communication with family, clinicians and the health care system [52-55]. The CDS program that was evaluated in this study attempts to bridge the gap between care delivered in health care settings and self-care in the home. There is a need for applications that improve outcomes across settings and patient populations [56]. Future studies are needed to assess the impact of this CDS program on patient outcomes.

Through this process, we identified patient barriers to use of CDS and clinicians' concerns about patients using CDS for self-management. From these barriers and concerns, we derived Design Objectives for CDS for symptom self-management, which included ensuring patient safety, communicating clinical concepts effectively, promoting communication with clinicians, supporting patient activation and facilitating navigation and use. These objectives may be useful to inform the design of CDS systems for symptom self-management of other conditions.

The barriers we identified for CDS for cancer symptom self-management had similarities and differences to barriers associated with self-management in patients with nonmalignant conditions $[57,58]$. Similar barriers included lack of knowledge, poor communication between patients and clinicians, and logistical issues in obtaining care. However, in contrast to the patients who did not have cancer, the cancer patients did not report barriers related to physical limitations, financial constraints, a need for social and emotional support, or challenges adhering to treatment $[57,58]$. Other differences in concerns that we noted between patients with cancer and those with non-malignant conditions were that cancer patients and their caregivers expressed concerns related to ensuring patient safety and negative health beliefs about use of narcotic pain medications. Shumacher and colleagues $[59,60]$ examined pain management processes among cancer patients and their caregivers and found similar concerns related to ensuring patient safety, especially in the context of narcotic pain medications. Patients and their caregivers had little interaction with clinicians in the home setting and had to master complex tasks related to taking their medications and reported that they felt that they had to be the final safety check. 


\section{Limitations}

The sample for this study was drawn from one institution using purposive sampling so it is not representative of all cancer patients. All of the patients and their caregivers in this study indicated that they used the Internet for seeking health information at least sometimes. This rate is higher than the $72 \%$ of Internet users found in the 2014 Pew Research survey [61]. Our rates for Internet usage may be higher as the majority of our sample had greater than a high school education. Factors associated with lower access of the Internet are older age, lower education and lower income [62]. Another limitation is that the majority of the sample was Caucasian and had higher levels of education. Further testing of this approach in a more diverse group of patients with cancer is warranted. Although the use of a simulated model provided a practical and economical approach to iterative development of the CDS tool, this approach did not allow for real time navigation through the algorithms for patients. This would be the next step in the development process.

\section{Conclusions}

The boundaries of health care are expanding and patients and their caregivers often have to self-manage complex cancer care at home. Thus, patient-centered decision support that meets this need is important and timely. Our system provides tailored information that informs patients when to call their clinicians, provides a script about what to tell tem about their symptom and specific suggestions about how the self manage their symptoms at home. Patients and their caregivers rated SAMI-Self-Care as highly acceptable and found the recommendations helpful. The patient-centered CDS design objectives we derived for cancer symptom selfmanagement may be applicable for the self-management of other conditions.

\section{Abbreviations \\ CDS: Clinical decision support; SAMI-Self-Care: Symptom Assessment and Management Intervention - Self Care}

\footnotetext{
Acknowledgements

We acknowledged the significant contributions of the expert panel in selecting the patient-focused decision-support project and refining the content and design of the decision support tools specified through this project. In addition to the co-authors of this manuscript, members of this expert panel included Annmarie Uliano, Richard Boyajian, MS; Jane Brzozowski, MS and Drs. Aymen Elfiky, Anne Gross, Joseph Jacobson, Christopher Lathan, and Larry Shulman. We also acknowledge the contributions of the DanaFarber Harvard Comprehensive Cancer Center Health Communication Core of for their contributions to the design and development of the SAMI-SC prototype. The authors also wish to thank the participants who shared their valuable time and effort. We appreciate the data collection contributions of research coordinator Maribel Melendez and Taylor Hendel for manuscript preparation.
}

\section{Author contributions}

MEC participated in conception of the project, data collection, analyses and interpretation of data, writing and revising the manuscript, final approval of the manuscript and is accountable for the quality of work. JLA participated in conception of the project, analyses and interpretation of data, writing and revising the manuscript, final approval of the manuscript and is accountable for the quality of work. DLB participated in conception of the project, interpretation of data, writing and revising the manuscript, final approval of the manuscript and is accountable for the quality of work. MSR participated in conception of the project, interpretation of data, writing and revising the manuscript, final approval of the manuscript and is accountable for the quality of work. IMB participated in conception of the project, interpretation of data, writing and revising the manuscript, final approval of the manuscript and is accountable for the quality of work. Patient stakeholder, JP,

participated in conception of the project, interpretation of data, writing and revising the manuscript, final approval of the manuscript and is accountable for the quality of work. MMN participated in data collection, analyses and interpretation of data, writing and revising the manuscript, final approval of the manuscript and is accountable for the quality of work. DFL participated in conception of the project, analyses and interpretation of data, writing and revising the manuscript, final approval of the manuscript and is accountable for the quality of work. All authors read and approved the final manuscript.

\section{Funding}

This work was supported by The Patient Centered Outcomes Research Institute Grant PI-12-001.

\section{Availability of data and materials}

The datasets used and/or analyzed during the current study are available from the corresponding author on reasonable request.

\section{Ethics approval and consent to participate}

This study was approved by the Dana-Farber Cancer Institute Institutional Review board (12-300). Informed consent was obtained from all individual participants included in the study.

\section{Competing interests}

The authors declare that they have no competing interests.

\section{Publisher's Note}

Springer Nature remains neutral with regard to jurisdictional claims in published maps and institutional affiliations.

\section{Author details}

${ }^{1}$ The Phyllis F. Cantor Center, Dana-Farber Cancer Institute, 450 Brookline Avenue, Boston, MA 02115, USA. ²Department of Psychosocial Oncology and Palliative Care, Dana-Farber Cancer Institute, 450 Brookline Avenue, Boston, MA 02115, USA. ${ }^{3}$ The Phyllis F. Cantor Center and the Department of Medicine, Dana-Farber Cancer Institute, 450 Brookline Ave, LW-512, Boston, MA 02115, USA. ${ }^{4}$ Lowe Center for Thoracic Oncology, Dana-Farber Cancer Institute, 450 Brookline Avenue, Boston, MA 02115, USA. ${ }^{5}$ Klesis Healthcare and Department of Family Medicine, Durham, NC 27705, USA. ${ }^{6}$ Department of Family Medicine, Duke University Medical Center, 2100 Erwin Road, Durham, NC 27710, USA.

Received: 4 August 2017 Accepted: 27 April 2018

Published online: 29 May 2018

\section{References}

1. Institute of Medicine Committee on Quality of Health Care in A. Crossing the quality chasm: a new health system for the 21st century. Washington (DC): National Academies Press (US) Copyright 2001 by the National Academy of Sciences. All rights reserved; 2001.

2. Patient Self-Management Support Programs: An Evaluation. Final Contract Report [http://www.orau.gov/ahrq/sms_report_08.asp?p=browse_guide]. Accessed Feb 2016.

3. McCorkle R, Ercolano E, Lazenby M, Schulman-Green D, Schilling LS, Lorig K, Wagner EH. Self-management: enabling and empowering patients living with cancer as a chronic illness. CA Cancer J Clin. 2011;61(1):50-62. 
4. Schulman-Green D, Bradley EH, Knobf MT, Prigerson H, DiGiovanna MP, McCorkle R. Self-management and transitions in women with advanced breast cancer. J Pain Symptom Manag. 2011;42(4):517-25.

5. Schulman-Green D, Bradley EH, Nicholson NR, Jr., George E, Indeck A, McCorkle R: One step at a time: self-management and transitions among women with ovarian cancer. Oncol Nurs Forum 2012, 39(4):354-360.

6. Bodenheimer T, Lorig K, Holman H, Grumbach K. Patient self-management of chronic disease in primary care. JAMA. 2002;288(19):2469-75.

7. Warsi A, Wang PS, LaValley MP, Avorn J, Solomon DH. Self-management education programs in chronic disease: a systematic review and methodological critique of the literature. Arch Intern Med. 2004;164(15):1641-9.

8. Lorig KR, Sobel DS, Stewart AL, Brown BW Jr, Bandura A, Ritter P, Gonzalez VM, Laurent DD, Holman HR. Evidence suggesting that a chronic disease self-management program can improve health status while reducing hospitalization: a randomized trial. Med Care. 1999:37(1):5-14.

9. McKay HGG, Russell E, Feil EG, Boles SM, Barrera M Jr. Internet-based diabetes self-management and support: initial outcomes from the diabetes network project. Rehabil Psychol. 2002;47(1):31-48.

10. Mooney KH, Beck SL, Friedman RH, Farzanfar R, Wong B. Automated monitoring of symptoms during ambulatory chemotherapy and oncology providers' use of the information: a randomized controlled clinical trial. Support Care Cancer. 2014;22(9):2343-50.

11. Ruland CM, Andersen T, Jeneson A, Moore S, Grimsbo GH, Borosund E, Ellison MC. Effects of an internet support system to assist cancer patients in reducing symptom distress: a randomized controlled trial. Cancer Nurs. 2013;36(1):6-17.

12. Berry DL, Hong F, Halpenny B, Partridge A, Fox E, Fann JR, Wolpin S, Lober WB, Bush N, Parvathaneni U, et al. The electronic self report assessment and intervention for cancer: promoting patient verbal reporting of symptom and quality of life issues in a randomized controlled trial. BMC Cancer. 2014;14:513.

13. Cleeland CS, Wang XS, Shi Q, Mendoza TR, Wright SL, Berry MD, Malveaux D, Shah PK, Gning I, Hofstetter WL, et al. Automated symptom alerts reduce postoperative symptom severity after cancer surgery: a randomized controlled clinical trial. J Clin Oncol Off J Am Soc Clin Oncol. 2011;29(8):994-1000.

14. Barlow J, Wright C, Sheasby J, Turner A, Hainsworth J. Self-management approaches for people with chronic conditions: a review. Patient Educ Couns. 2002;48(2):177-87.

15. Samoocha D, Bruinvels DJ, Elbers NA, Anema JR, van $\operatorname{der}$ Beek AJ. Effectiveness of web-based interventions on patient empowerment: a systematic review and meta-analysis. J Med Internet Res. 2010;12(2):e23.

16. Gustafson DH, Hawkins R, McTavish F, Pingree S, Chen WC, Volrathongchai $K_{\text {, }}$ Stengle W, Stewart JA, Serlin RC. Internet-based interactive support for Cancer patients: are integrated systems better? J Commun. 2008;58(2):238-57.

17. Marie N, Luckett T, Davidson PM, Lovell M, Lal S. Optimal patient education for cancer pain: a systematic review and theory-based metaanalysis. Support Care Cancer. 2013;21(12):3529-37.

18. Yun YH, Lee KS, Kim YW, Park SY, Lee ES, Noh DY, Kim S, Oh JH, Jung SY, Chung KW et al: Web-based tailored education program for disease-free cancer survivors with cancer-related fatigue: a randomized controlled trial. J Clin Oncol Off J Am Soc Clin Oncol 2012, 30(12):1296-1303.

19. Lewis FM, Brandt PA, Cochrane BB, Griffith KA, Grant M, Haase JE, Houldin AD, Post-White J, Zahlis EH, Shands ME. The enhancing connections program: a six-state randomized clinical trial of a cancer parenting program. J Consult Clin Psychol. 2015;83(1):12-23.

20. Ruland CM, Jeneson A, Andersen T, Andersen R, Slaughter $L$, Bente Schjodt O, Moore SM. Designing tailored internet support to assist cancer patients in illness management. AMIA Annu Symp Proc. 2007;2007:635-9.

21. Osheroff JA, Teich JM, Middleton B, Steen EB, Wright A, Detmer DE. A roadmap for national action on clinical decision support. J Am Med Inform Assoc. 2007;14(2):141-5.

22. Head BA, Keeney C, Studts JL, Khayat M, Bumpous J, Pfeifer M. Feasibility and acceptance of a telehealth intervention to promote symptom management during treatment for head and neck Cancer. J Support Oncol. 2011;9(1):e1-e11.

23. Weaver A, Young AM, Rowntree J, Townsend N, Pearson S, Smith J, Gibson O, Cobern W, Larsen M, Tarassenko L. Application of mobile phone technology for managing chemotherapy-associated side-effects. Ann Oncol. 2007;18(11): 1887-92.

24. Berry DL, Hong F, Halpenny B, Partridge AH, Fann JR, Wolpin S, Lober WB, Bush NE, Parvathaneni U, Back AL, et al. Electronic self-report assessment for cancer and self-care support: results of a multicenter randomized trial. J Clin Oncol Off J Am Soc Clin Oncol. 2014;32(3):199-205.
25. Ruland CM, Maffei RM, Borosund E, Krahn A, Andersen T, Grimsbo GH Evaluation of different features of an eHealth application for personalized illness management support: cancer patients' use and appraisal of usefulness. Int J Med Inform. 2013;82(7):593-603.

26. Creswell JW, Plano Clark VL. Designing and conducting mixed methods research, 2nd edn. Thousand Oaks: Sage Publications; 2011.

27. Fervers B, Burgers JS, Haugh MC, Latreille J, Mlika-Cabanne N, Paquet L, Coulombe M, Poirier M, Burnand B. Adaptation of clinical guidelines: literature review and proposition for a framework and procedure. Int I Qual Health Care. 2006;18(3):167-76.

28. Amer YS, Elzalabany MM, Omar TI, Ibrahim AG, Dowidar NL. The 'Adapted ADAPTE': an approach to improve utilization of the ADAPTE guideline adaptation resource toolkit in the Alexandria Center for Evidence-Based Clinical Practice Guidelines. J Eval Clin Pract. 2015;21(6):1095-106.

29. Fervers B, Burgers JS, Voellinger R, Brouwers M, Browman GP, Graham ID, Harrison MB, Latreille J, Mlika-Cabane N, Paquet L, et al. Guideline adaptation: an approach to enhance efficiency in quideline development and improve utilisation. BMJ Qual Saf. 2011;20(3):228-36.

30. Ruegg TA. A nurse practitioner-led urgent care center: meeting the needs of the patient with cancer. Clin J Oncol Nurs. 2013;17(4):E52-7.

31. Cooley ME, Lobach DF, Johns E, Halpenny B, Saunders TA, Del Fiol G, Rabin MS, Calarese P, Berenbaum IL, Zaner K, et al. Creating computable algorithms for symptom management in an outpatient thoracic oncology setting. J Pain Symptom Manag. 2013;46(6):911-24. e911

32. Scariot CA, Heemann A, Padovani S. Understanding the collaborativeparticipatory design. Work (Reading, Mass). 2012;41(Suppl 1):2701-5.

33. Revere $D$, Dixon BE, Hills R, Williams JL, Grannis SJ. Leveraging health information exchange to improve population health reporting processes: lessons in using a collaborative-participatory design process. EGEMS (Wash, DC). 2014;2(3):1082.

34. Collins D. Pretesting survey instruments: an overview of cognitive methods. Qual Life Res Int J Qual Life Asp Treat Care Rehab. 2003;12(3):229-38.

35. Bates DW, Kuperman GJ, Wang S, Gandhi T, Kittler A, Volk L, Spurr C, Khorasani R, Tanasijevic M, Middleton B. Ten commandments for effective clinical decision support: making the practice of evidence-based medicine a reality. J Am Med Inform Assoc. 2003;10(6):523-30.

36. Kawamoto K, Houlihan CA, Balas EA, Lobach DF. Improving clinical practice using clinical decision support systems: a systematic review of trials to identify features critical to success. BMJ. 2005;330(7494):765.

37. Crabtree BF, Yanoshik MK, Miller WL, O'Connor PJ. Successful focus groups: advancing the state of the art. Thousand Oaks: SAGE Publications, Inc.; 1993.

38. Virzi R. Refining the test phase of usability evaluation: how many subjects is enough? Hum Factors. 1992;34(4):457-68.

39. Tariman JD, Berry DL, Halpenny B, Wolpin S, Schepp K. Validation and testing of the acceptability E-scale for web-based patient-reported outcomes in cancer care. Appl Nurs Res. 2011;24(1):53-8.

40. Berry DL, Halpenny B, Wolpin S, Davison BJ, Ellis WJ, Lober WB, McReynolds J, Wulff J. Development and evaluation of the personal patient profile-prostate (P3P), a web-based decision support system for men newly diagnosed with localized prostate cancer. J Med Internet Res. 2010;12(4):e67.

41. Mullen KH, Berry DL, Zierler BK. Computerized symptom and quality-of-life assessment for patients with cancer part II: acceptability and usability. Oncol Nurs Forum. 2004;31(5):E84-9.

42. Elo S, Kyngas $\mathrm{H}$. The qualitative content analysis process. J Adv Nurs. 2008; 62(1):107-15.

43. Coleman K, Austin BT, Brach C, Wagner EH. Evidence on the chronic care model in the new millennium: thus far, the evidence on the chronic care model is encouraging, but we need better tools to help practices improve their systems. Health affairs (Project Hope). 2009;28(1):75-85.

44. Lobach DF, Johns EB, Halpenny B, Saunders TA, Brzozowski J, Del Fiol G, Berry DL, Braun IM, Finn K, Wolfe J et al: Increasing complexity in rule-based clinical decision support: the symptom assessment and management intervention. JMIR Med Inform 2016, 4(4):e36.

45. Johnson CM, Johnson TR, Zhang J. A user-centered framework for redesigning health care interfaces. J Biomed Inform. 2005;38(1):75-87.

46. Mirkovic J, Kaufman DR, Ruland CM. Supporting cancer patients in illness management: usability evaluation of a mobile app. JMIR mHealth and uHealth. 2014;2(3):e33. doi:https://doi.org/10.2196/mhealth.3359.

47. Gordon DB, Dahl JL, Miaskowski C, McCarberg B, Todd KH, Paice JA, Lipman AG, Bookbinder M, Sanders SH, Turk DC, et al. American pain society recommendations for improving the quality of acute and cancer pain 
management: American pain society quality of care task force. Arch Intern Med. 2005;165(14):1574-80.

48. Isaac T, Stuver SO, Davis RB, Block S, Weeks JC, Berry DL, Weingart SN . Incidence of severe pain in newly diagnosed ambulatory patients with stage IV cancer. Pain Res Manag. 2012, 17;(5):347-52.

49. Zhao F, Chang VT, Cleeland C, Cleary JF, Mitchell EP, Wagner LI, Fisch MJ. Determinants of pain severity changes in ambulatory patients with cancer: an analysis from eastern cooperative oncology group trial E2Z02. J Clin Oncol. 2014;32(4):312-9.

50. Berry DL, Nayak MM, Abrahm JL, Braun I, Rabin MS, Cooley ME. Clinician perspectives on symptom and quality of life experiences of patients during cancer therapies: implications for eHealth. Psycho-Oncology. 2017;

51. Horsky J, Schiff GD, Johnston D, Mercincavage L, Bell D, Middleton B. Interface design principles for usable decision support: a targeted review of best practices for clinical prescribing interventions. J Biomed Inform. 2012; 45(6):1202-16

52. Ozkaynak M, Brennan PF, Hanauer DA, Johnson S, Aarts J, Zheng K, Haque SN. Patient-centered care requires a patient-oriented workflow model. J Am Med Inform Assoc. 2013;20(e1):e14-6.

53. Ahern DK, Woods SS, Lightowler MC, Finley SW, Houston TK. Promise of and potential for patient-facing technologies to enable meaningful use. Am J Prev Med. 2011:40(5 Suppl 2):S162-72.

54. Clauser SB, Wagner EH, Aiello Bowles EJ, Tuzzio L, Greene SM. Improving modern cancer care through information technology. Am J Prev Med. 2011; 40(5 Suppl 2):S198-207.

55. Valdez RS, Holden RJ, Novak LL, Veinot TC. Transforming consumer health informatics through a patient work framework: connecting patients to context. J Am Med Inform Assoc. 2015;22(1):2-10.

56. McCoy AB, Wright A, Eysenbach G, Malin BA, Patterson ES, Xu H, Sittig DF. State of the art in clinical informatics: evidence and examples. Yearb Med inform. 2013;8(1):13-9.

57. Bayliss EA, Steiner JF, Fernald DH, Crane LA, Main DS. Descriptions of barriers to self-care by persons with comorbid chronic diseases. Ann Fam Med. 2003;1(1):15-21.

58. Fort MP, Alvarado-Molina N, Pena L, Mendoza Montano C, Murrillo S, Martinez H. Barriers and facilitating factors for disease self-management: a qualitative analysis of perceptions of patients receiving care for type 2 diabetes and/or hypertension in San Jose, Costa Rica and Tuxtla Gutierrez, Mexico. BMC Fam Pract. 2013;14:131.

59. Schumacher KL, Plano Clark VL, West CM, Dodd MJ, Rabow MW, Miaskowski C. Pain medication management processes used by oncology outpatients and family caregivers part II: home and lifestyle contexts. J Pain Symptom Manag. 2014;48(5):784-96.

60. Schumacher KL, Plano Clark VL, West CM, Dodd MJ, Rabow MW, Miaskowsk C. Pain medication management processes used by oncology outpatients and family caregivers part I: health systems contexts. J Pain Symptom Manag. 2014:48(5):770-83.

61. Fox S, Duggan M. Health online 2013. Pew Research Center. Internet, Science, and Tech. Internet. 15 Jan 2013. (http://www.pewinternet.org/2013/01/15/ health-online-2013/

62. Smith A, PRCl. Science and technology: technology adoption by lower income populations. San Diego: American Public Human Services Association, IT Solution Management; 2013.

63. NCCN. Clinical practice guidelines in oncology. Adult Cancer Pain. Version 2. 2014 [http://williams.medicine.wisc.edu/pain.pdf

\section{Ready to submit your research? Choose BMC and benefit from:}

- fast, convenient online submission

- thorough peer review by experienced researchers in your field

- rapid publication on acceptance

- support for research data, including large and complex data types

- gold Open Access which fosters wider collaboration and increased citations

- maximum visibility for your research: over $100 \mathrm{M}$ website views per year

At BMC, research is always in progress.

Learn more biomedcentral.com/submissions 